\title{
STRATEGI PEMASARAN ROTI BAKAR JAMIN HALAL NIKMAT (JHN) WANGI MADU STUDI KASUS DESA SEPUK TANJUNG KACAMATAN SEBAWI KABUPATEN SAMBAS
}

\author{
IRMA FAHRIZAL BUTSI NINGSIH, SUSILAWATI
}

\author{
Teknik Mesin Pertanian, Politeknik Negeri Sambas, Sambas ${ }^{1}$ \\ Agrobisnis, Politeknik Negeri Sambas, Sambas ${ }^{2}$ \\ e-mail: irmafbn@yahoo.co.id
}

\begin{abstract}
Bread is an additional food favored by people in Sambas Regency. One of the businesses engaged in making baked bread is "Halal and Delicious Guarantee (Jaminan Halal Nikmat-JHN)" bread of Wangi Madu which is located in Sepuk Tanjung Village, Sebawi District, Sambas Regency. This JHN was founded by Mr. Tiong Nyit Kong in 2010, with a household scale. Production, sales and production leftover from January to March 2017 have decreased every month. One of the factors that causes the production and sales of bread to decline monthly is the reduced purchasing power of consumers against JHN's bread. Therefore, it is necessary to examine how "Marketing Strategy for Baked Bread" Halal Delicious Guarantee of Wangi Madu (Scented Honey) in Sepuk Tanjung Village, Sebawi District, Sambas Regency". In determining the marketing strategy, analysis of internal and external factors was used, then processed using SWOT analysis. From the IFE / EFE analysis, obtained seven strengths with the main strength is to have complete permits and halal certificates with a value of 0,313. Six weaknesses, with its main weakness is that the product is not durable with a value of 0,307. Four opportunities, the biggest opportunity with a value of 0,508 is Consumer Loyalty. Four threats with the main threat value of 0.463 is the rise of online cake traders / sellers. Based on the results of the SWOT analysis, Ten strategies are obtained, namely: introducing current products and expanding the marketing area, developing product variants or adding new products, openness and cooperation, production and sales forecasting, improving product packaging, improving product quality by adding flavors and size, recruiting personnel in certain fields and increasing vehicles, increasing creativity for processing new products that are more in demand by consumers, increasing promotional efforts, creating websites and social media accounts about JHN's Bread.
\end{abstract}

Keywords : bread, Halal Delicious Guarantee (Jaminan Halal Nikmat-JHN), marketing strategy

\section{PENDAHULUAN}

Perkembangan industri usaha kecil dan menengah memiliki peranan yang penting dalam perekonomian baik di Indonesia maupun di negara lainnya. Sektor industri merupakan sektor yang paling utama dalam mendukung perekonomian di Indonesia. Menurut Dumairy (1996), produk-produk industri selalu memiliki nilai tukar yang tinggi atau lebih menguntungkan serta menciptakan nilai tambah yang lebih besar dibanding produk-produk sektor lain Pelaku bisnis (produsen, peyalur, pedagang, dan investor) lebih suka berkecimpung dalam bidang industri karena 
sektor ini memberikan marjin keuntungan yang lebih menarik. Fokus perhatian pembangunan sektor ekonomi dirasa perlu diberikan pada subsektor industri kecil dan kerajinan yang memiliki potensi dan peranan penting.

Menurut Suyanto (2004), untuk mengembangkan produk, suatu selain perlu membenahi faktor- faktor produksi, tindakan pemasaran juga sangat berperan didalamnya. Melalui pengembangan produk, tujuan yang ingin dicapai dapat sesuai dengan rencana yang telah ditetapkan, dan juga sesuai dengan permintaan pasar. Pemasar menggunakan sejumlah peralatan untuk memperoleh tanggapan yang diinginkan target pasarnya. Peralatan tersebut adalah bauran pemasaran dan mengelompokkan bauran pemasaran tersebut dalam empat kelompok besar yang disingkat 4P, yaitu product (produk), price (harga), place (tempat), dan promotion (promosi).

Roti merupakan makanan tambahan yang digemari oleh masyarakat di Kabupaten Sambas. Salah satu usaha yang bergerak dalam pembuatan roti bakar adalah Roti Bakar "Jamin Halal Nikmat (JHN)" Wangi Madu yang berlokasi di Desa Sepuk Tanjung Kecamatan Sebawi Kabupaten Sambas. JHN ini didirikan oleh Bapak Tiong Nyit Kong pada tahun 2010, dengan skala rumah tangga. Usaha industri roti bakar ini belum banyak dilakukan oleh penduduk di Kecamatan Tebas. Seiring dengan pertambahan jumlah penduduk, maka usaha ini akan memberikan peluang yang cerah bagi pelaku usaha roti bakar. Hal ini menyebabkan usaha industri roti bakar JHN yang didirikan pada tahun 2010 masih melakukan usahanya sampai sekarang. Adapun data produksi roti bakar JHN dapat dilihat pada Tabel 1.

Tabel 1. Produksi dan Penjualan Roti Bakar JHN Tahun 2017

\begin{tabular}{clrrr}
\hline No & Bulan & $\begin{array}{c}\text { Hasil produksi } \\
\text { (buah/bulan) }\end{array}$ & $\begin{array}{c}\text { Hasil Penjualan } \\
\text { (buah/bulan) }\end{array}$ & $\begin{array}{c}\text { Sisa Produksi } \\
\text { (buah) }\end{array}$ \\
\hline 1 & Jan & 175.000 & 174.850 & 150 \\
2 & Feb & 155.500 & 155.100 & 400 \\
3 & Mar & 145.100 & 144.910 & 190 \\
\hline Jumlah & & $\mathbf{4 7 5 . 6 0 0}$ & $\mathbf{4 7 4 . 8 6 0}$ & $\mathbf{7 4 0}$
\end{tabular}

Sumber : Data Primer, 2017

Tabel 1. menunjukkan bahwa hasil produksi, penjualan, dan sisa produksi dari bulan Januari hingga Maret tahun 2017 berjumlah hasil produksi sebanyak 475.600 buah, hasil penjualan sebanyak 474.860 buah, dan sisa produksi sebanyak 740 buah. Sejak Bulan Januari hingga Maret 2017, hasil produksi dan penjualan mengalami penurunan pada setiap bulannya. Sehingga hal ini menyebabkan jumlah produksi per bulannya dikurangi agar perusahaan tidak mengalami kerugian yang besar. Salah satu faktor yang menyebabkan hasil produksi dan penjualan roti menurun pada perbulannya adalah berkurangnya daya beli konsumen terhadap roti bakar perusahaan JHN. Oleh karena itu, perlu diteliti bagaimana "Strategi Pemasaran Roti Bakar "Jamin Halal Nikmat" Wangi Madu di Desa Sepuk Tanjung Kecamatan Sebawi Kabupaten Sambas".

Berdasarkan penjelasan di atas, maka rumusan masalah yang diangkat adalah bagaimana strategi pemasaran roti bakar "Jamin Halal Nikmat (JHN)" Wangi Madu di Desa Sepuk Tanjung Kecamatan Tebas Kabupaten Sabas?. 


\section{METODE PENELITIAN}

Metode penelitian yang digunakan dalam penelitian adalah metode penelitian deskriptif, yaitu studi untuk menemukan fakta dengan interpretasi yang tepat berdasarkan data-data bersifat eksploratif yang bertujuan untuk mengenal fenomena penelitian selanjutnya. Metode pengumpulan data yang dipergunakan dalam penelitian ini adalah wawancara dengan bantuan pedoman wawancara pertanyaan (kuisioner).Penelitian ini merupakan penelitian studi kasus yang objek penelitiannya adalah perusahaan roti bakar Jamin Halal Nikmat (JHN) Wangi Madu yang berlokasi di Desa Sepuk Tanjung Kecamatan Tebas Kabupaten Sambas.

\section{HASIL DAN PEMBAHASAN}

\section{Identifikasi Faktor Internal dan Eksternal}

Faktor - faktor strategis internal dapat dilihat pada Tabel 2 dan faktor - faktor strategis eksternal dapat dilihat pada Tabel 3.

Tabel 2. Faktor-Faktor Strategis Internal Roti Bakar JHNTahun 2017

\begin{tabular}{|c|c|}
\hline Kekuatan & Kelemahan \\
\hline tidak menggunakan & 1. Produk tidak tahan lama \\
\hline pengawet & 2. Tanggal kadaluarsa tidak tercantum \\
\hline 2. Memiliki beraneka cita rasa & di kemasan \\
\hline $\begin{array}{l}\text { (coklat, srikaya dan kelapa) } \\
\text { 3. Harga terjangkau }\end{array}$ & $\begin{array}{l}\text { 3. Manajer merangkap administrasi } \\
\text { dan produksi }\end{array}$ \\
\hline 4. Sirkulasi produk terdokumentasi & 4. Jumlah tenaga dan kendaraan \\
\hline 5. Memiliki pelanggan tetap & pemasaran sedikit \\
\hline $\begin{array}{l}\text { 6. Memiliki perijinan lengkap dan } \\
\text { sertifikat halal }\end{array}$ & $\begin{array}{l}\text { 5. Belum ada promosi yang intens } \\
\text { 6. Kemasan sangat sederhana }\end{array}$ \\
\hline $\begin{array}{l}\text { 7. Memiliki kendaraan pemasaran } \\
\text { sendiri }\end{array}$ & \\
\hline
\end{tabular}

Sumber: Analisis Data Primer, 2017

Tabel 3. Faktor-Faktor Strategis Eksternal Roti Bakar JHN Tahun 2017

\begin{tabular}{llll}
\hline \multicolumn{2}{c}{ Kekuatan } & \multicolumn{2}{c}{ Kelemahan } \\
\hline 1. Menjadi tempat magang siswa & 1. $\begin{array}{l}\text { Munculnya usaha sejenis } \\
\text { SMK dan mahasiswa }\end{array}$ & 2. $\begin{array}{l}\text { Perekonomian tidak setabil } \\
\text { sehingga daya beli masyarakat } \\
\text { menurun }\end{array}$ \\
$\begin{array}{l}\text { 2. Dapat memperluas jaringan } \\
\text { pemasaran }\end{array}$ & $\begin{array}{l}\text { Maraknya pedagang/penjual kue } \\
\text { Loyalitas Konsumen Adanya } \\
\text { kemudahan untuk mendapatkan } \\
\text { bantuan dari dinas terkait }\end{array}$ & $\begin{array}{l}\text { online Kenaikan BBM, Listrik, } \\
\text { Pajak dan Bahan Baku }\end{array}$ \\
\hline
\end{tabular}

Sumber: Analisis Data Primer, 2017

\section{Analisis Input}

\section{(a) Matriks Internal Faktor Evaluation (IFE)}

Hasil analisis matriks IFE dapat dilihat pada Tabel 4, diperoleh total nilai terbobot sebesar 3,54. Hal ini menunjukkan bahwa Roti Bakar JHN Wangi Madu berada pada posisi kuat dalam memanfaatkan kekuatan yang dimiliki dan mampu mengatasi kelemahan yang ada.

Kekuatan terbesar dan menjadi kekuatan utama yang dimiliki oleh JHN dengan nilai 0,313 adalah memiliki perijinan lengkap dan sertifikat halal. Hal ini 
dikarenakan pada umumnya usaha sejenis dengan skala rumah tangga atau usaha kecil menengah masih jarang yang memiliki sertifikat halal. Rata-rata usaha yang sejenis hanya mengantongi PIRT saja. Untuk mendapatkan sertifikat halal perlu usaha yang besar untuk mendapatkannya.

Berdasarkan dari hasil wawancara dengan pemilik JHN Bapak Tjong Nyit Kong, untuk mendapatkan sertifikat halal ia harus melengkapi segala persyaratan untuk mendapatkan sertifikat tersebut, diantaranya : Bahan-bahan yang digunakan dalam produksi tidak berasal dari bahan haram atau najis, sensori produk tidak boleh memiliki kecenderungan bau atau rasa yang mengarah ke produk haram / telah dinyatakan haram oleh MUI, Fasilitas produksi harus dijamin tidak adanya kontaminasi silang dengan bahan/produk yang haram/najis, tenaga kerja bagian produksi di JHN 100\% muslim, dilakukan audit oleh tim MUI, memberikan sampel produk pada MUI, Lokasi berada jauh dari lingkungan peternakan, dan masih banyak persyaratan lainnya yang harus dipenuhi baik secara administrasi maupun teknis. Sertifikat halal akan diperbaharui setiap 3 tahun sekali, dengan kembali mengusulkan dan melengkapi persyaratan serta audit oleh tim MUI.

Kelemahan utamanya dengan nilai 0,307 adalah produk tidak tahan lama. Hal ini dikarenakan produk JHN tidak menggunakan bahan pengawet, sehingga produk hanya bisa bertahan untuk dikonsumsi selama 10 hari. JHN memberikan masa kadaluarsa pada produknya hanya selama 7 hari. Setiap 7 hari sekali produk yang tidak terjual diambil dan diganti dengan yang baru.

Tabel 4. Hasil Analisis Matriks IFE

\begin{tabular}{|c|c|c|c|}
\hline Faktor & Rating & Bobot & Skor \\
\hline \multicolumn{4}{|l|}{ Kekuatan (A) } \\
\hline 1 Produk tidak menggunakan pengawet & 4 & 0.077 & 0.306 \\
\hline $\begin{array}{l}2 \text { Memiliki beraneka cita rasa (coklat, srikaya, } \\
\text { kelapa) }\end{array}$ & 4 & 0.077 & 0.310 \\
\hline 3 Harga terjangkau (Rp 1.000/buah) & 3 & 0.073 & 0.218 \\
\hline 4 Sirkulasi produk terdokumentasi & 4 & 0.078 & 0.310 \\
\hline 5 Memiliki pelanggan tetap & 4 & 0.077 & 0.309 \\
\hline 6 Memiliki perijinan lengkap dan sertifikat halal & 4 & 0.078 & 0.313 \\
\hline \multirow[t]{2}{*}{$7 \mathrm{Me}$} & 3 & 0.079 & 0.236 \\
\hline & & $\mathbf{0 . 5 3 8}$ & 2.001 \\
\hline \multicolumn{4}{|l|}{ Kelemahan (B) } \\
\hline 1 Produk tidak tahan lama & 4 & 0.077 & 0.307 \\
\hline 2 Tanggal kadaluarsa tidak tercantum di kemasan & 4 & 0.076 & 0.305 \\
\hline 3 Manajer merangkap administrasi dan produksi & 3 & 0.077 & 0.231 \\
\hline 4 Jumlah tenaga pemasaran dan kendaraan sedikit & 3 & 0.078 & 0.234 \\
\hline 5 Belum ada promosi yang intens & 3 & 0.075 & 0.224 \\
\hline \multirow[t]{2}{*}{6 Kemasan sangat sederhana } & 3 & 0.079 & 0.238 \\
\hline & & 0.462 & 1.538 \\
\hline TOTAL IFE $(A+B)$ & & 1.000 & 3.540 \\
\hline
\end{tabular}

Sumber: Analisis Data Primer, 2017 
(b) Matriks Eksternal Faktor Evaluation (EFE)

Hasil analisis matriks EFE dapat dilihat pada Tabel 5

Tabel 5. Analisis Matriks EFE

\begin{tabular}{|c|c|c|c|}
\hline Faktor & Rating & Bobot & Skor \\
\hline \multicolumn{4}{|l|}{ Peluang (A) } \\
\hline $\begin{array}{l}1 \text { Menjadi tempat magang siswa SMK dan } \\
\text { mahasiswa }\end{array}$ & 4 & 0.126 & 0.504 \\
\hline 2 Dapat memperluas jaringan & 4 & 0.123 & 0.490 \\
\hline 3 Loyalitas Konsumen & 4 & 0.127 & 0.508 \\
\hline \multirow[t]{2}{*}{$\begin{array}{l}4 \text { Adanya kemudahan untuk mendapatkan bantuan } \\
\text { dari dinas terkait }\end{array}$} & 4 & 0.122 & 0.486 \\
\hline & & 0.497 & 1.988 \\
\hline \multicolumn{4}{|l|}{ Ancaman (B) } \\
\hline 1 Munculnya usaha sejenis & 3 & 0.130 & 0.390 \\
\hline $\begin{array}{l}2 \text { Perekonomian tidka stabil sehingga daya beli } \\
\text { masyarakat menurun }\end{array}$ & 3 & 0.129 & 0.386 \\
\hline 3 Maraknya pedagang/penjual kue online & 4 & 0.116 & 0.463 \\
\hline \multirow[t]{2}{*}{4 Kenaikan BBM, Listrik, Pajak, dan Bahan Baku } & 3 & 0.129 & 0.386 \\
\hline & & 0.503 & 1.624 \\
\hline TOTAL $(A+B)$ & & 1.000 & 3.613 \\
\hline
\end{tabular}

Sumber : Hasil Anaisis, 2017

Berdasarkan Tabel matriks EFE diperoleh total nilai terbobot sebesar 3,613. Hal ini menunjukkan bahwa Roti Bakar JHN Wangi Madu berada pada posisi kuat dalam memanfaatkan peluang yang dimiliki dalam mengatasi ancaman yang ada.

Peluang terbesar dan utama yang dimiliki oleh JHN dengan nilai 0,508 adalah Loyalitas Konsumen. Hal ini dikarenakan adanya kepercayaan dan komitmen para pelanggan terhadap produk Roti Bakar JHN Wangi Madu karena mereka mendapatkan kepuasan dari produk yang dihasilkan, selain itu harganya juga terjangkau. Hal ini bisa menjadi peluang yang menguntungkan, sebab konsumen yang sudah loyal dengan roti yang dijual akan melakukan pembelian secara rutin. Sistem pemasaran JHN secara konsinyasi sehingga pemilik toko juga ikut memasarkan / membantu menawarkan produk karena pemilik toko juga merasa diuntungkan ketika produk yang dititipkan cepat habis. Ancaman utama untuk JHN dengan nilai 0,463 adalah maraknya pedagang / penjual kue online. Hal ini dapat dilihat dari pesatnya perkembangan teknologi dan media sosial sehingga banyak bermunculan pedagang online dengan menggunakan facebook, whats app, BBM, line dan masih banyak lagi. Kelebihan dari pedagang online adalah produk langsung diantar ke konsumen dan pembayaran setelah barang / produk diterima.

\section{Matriks SWOT}

Berdasarkan analisis SWOT pada Tabel 6, terdapat 10 alternatif strategi yang akan digunakan oleh JHN untuk mengembangkan usahanya, yaitu:

\section{Strategi $S-O$}

a. Mengenalkan produk yang ada saat ini dan memperluas area pemasaran. 
b. Mengembangkan varian rasa produk atau menambah produk baru.

c. Keterbukaan dan kerjasama.

d. Peramalan Produksi dan Penjualan.

2. Strategi W - O

a. Memperbaiki kemasan produk.

b. Meningkatkan kualitas produk dengan menambah varian rasa maupun ukuran.

c. Merekrut tenaga di bidang tertentu dan menambah kendaraan.

\section{Strategi $\mathbf{S}-\mathbf{T}$}

Meningkatkan kreatifitas untuk pengolahan produk baru yang lebih diminati konsumen.

\section{Strategi W - T}

a. Peningkatan upaya promosi.

b. Membuat website dan akun media sosial tentang Roti JHN.

Tabel 6. Analisis SWOT

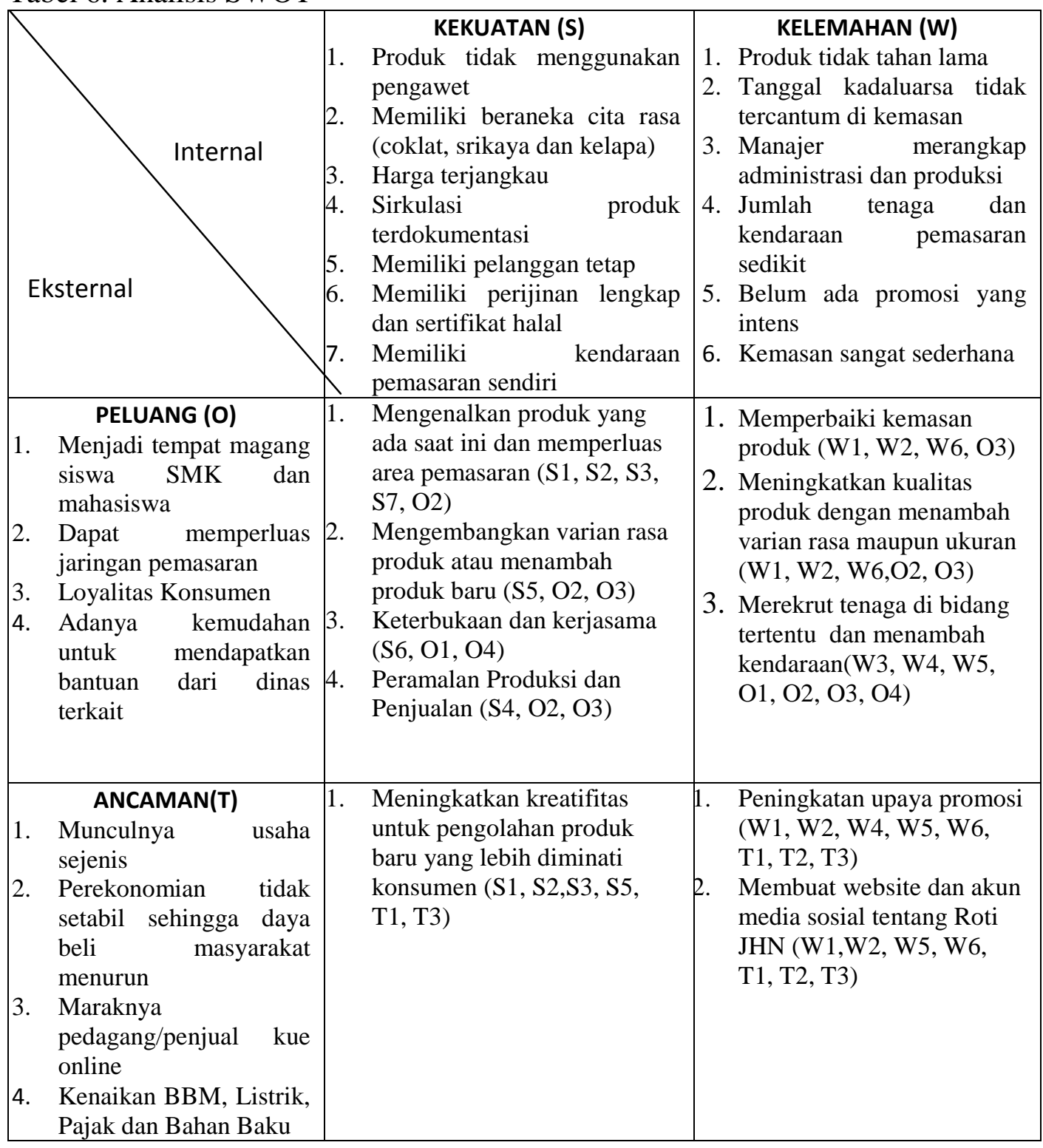




\section{KESIMPULAN DAN SARAN}

Berdasarkan hasil penelitian, kesimpulan yang diperoleh adalah

1. JHN memiliki 7 kekuatan dengan kekuatan utama adalah memiliki perijinan lengkap dan sertifikat halal dengan nilai 0,313. Untuk kelemahan, JHN memiliki 6 kelemahan, dengan kelemahan utamanya adalah produk tidak tahan lama dengan nilai 0,307. Untuk peluang JHN memiliki 4 peluang dan peluang terbesar yang dimiliki oleh JHN dengan nilai 0,508 adalah Loyalitas Konsumen. Sedangkan untuk ancaman JHN memiliki 4 ancaman dengan ancaman utama untuk JHN bernilai 0,463 adalah maraknya pedagang / penjual kue online.

2. Berdasarkan hasil analisis SWOT, diperoleh 10 strategi pemasaran roti bakar "Jamin Halal Nikmat (JHN)" Wangi Madu di Desa Sepuk Tanjung Kecamatan Tebas Kabupaten Sambas adalah :

a. Mengenalkan produk yang ada saat ini dan memperluas area pemasaran.

b. Mengembangkan varian rasa produk atau menambah produk baru.

c. Keterbukaan dan kerjasama.

d. Peramalan Produksi dan Penjualan.

e. Memperbaiki kemasan produk.

f. Meningkatkan kualitas produk dengan menambah varian rasa maupun ukuran.

g. Merekrut tenaga di bidang tertentu dan menambah kendaraan.

h. Meningkatkan kreatifitas untuk pengolahan produk baru yang lebih diminati konsumen.

i. Peningkatan upaya promosi.

j. Membuat website dan akun media sosial tentang Roti JHN.

Saran serta masukan kepada JHN untuk dapat menerapkan strategi yang diperoleh dari hasil analisis SWOT yang telah ada. Hal ini perlu dilakukan dengan harapan akan adanya peningkatan penjualan Roti Bakar "Jamin Halal Nikmat" Wangi Madu.

\section{DAFTAR PUSTAKA}

David, H.H. and R.A.Golberg. 1987. A Concept of Agribusiness. Harvard University

Hendro. 2011.Dasar-Dasar Kewirausahaan.Erlangga. Jakarta.

Kasmir, 2011.Kewirausahaan.PT Raja Grafindo Persada. Jakarta.

Kotler, Philip. 2000. Marketing Management, Analisis Planing, Implementation and Control, Prentice Hall. Edisi Pertama. Yogyakarta: Graha Ilmu.

Kotler, P. 2005. Manajamen Pemasaran, Jilid 1 dan 2. PT. Indeks Kelompok Gramedia. Jakarta.

Kotler, Philip dan Armstrong, Gary, 2008.Prinsip-Prinsip Pemasaran.Erlangga. Jakarta.

Laksana, Fajar. 2008. Manajemen Pemasaran. Edisi Pertama. Yogyakarta: Graha Ilmu.

Mudjajanto Setyo Eddy dan Yulianti Noor Lilik, 2007.Membuat Aneka Roti. Pemebar Swadaya. Jakarta.

Purnomo H. S., dan Zulkiefliansyah. 1999. Manajemen Strategi sebuah Konsep Pengantar. Penerbit Fakultas ekonomi UI, Jakarta. 
Rangkuti, F. 2001. Analisis SWOT : Teknik Membedah Kasus Bisnis. PT. Gramedia Pustaka Utama. Jakarta.

Singarimbun, Masni dan Effendi, Sofian, 2011. Metode Penelitian Survei. LP3ES. Jakarta.

Sunarya, Abas, Sudaryono dan Saefullah, Asep, 2011. Kewirausahaan. C.V Andi Offset. Yogyakarta.

Sutomo, Budi, 2007. Membuat Aneka Roti.Pustaka Pelangi. Jakarta.

Suyanto, 2004.Analisis dan Desain Aplikasi Multimedia untuk Pemasaran. Andi C.V Offset.Yogyakarta. 